\title{
Mapping pre-Columbian land use in Amazonia
}

Umberto Lombardo', C. McMichael², E. Kazuo Tamanaha³ and workshops participants

To improve climate models, climatologists need data on the world's past land use. We present the initial results of a multidisciplinary effort, which aims to (i) expand the database of Amazonian archaeological sites and (ii) reconstruct past land use in Amazonia.

Reconstructing pre-Columbian land-use patterns in Amazonia is crucial in assessing the possible influence that pre-contact (i.e. pre-Colonial) deforestation and postcontact reforestation had on global climate. Pre-contact populations of Amazonia are estimated to have been 5-8.4 million, decreasing by $95 \%$ due to disease, slavery and war following European conquest (Denevan 2014). This severe population collapse resulted in the abandonment of cultivated areas and re-colonization of those areas by natural vegetation. As Amazonia is one of the largest terrestrial players in the global carbon cycle, the post-contact reforestation is suggested to have sequestered sufficient atmospheric $\mathrm{CO}_{2}$ to contribute to the onset of the Little Ice Age (Dull et al. 2010). Many ecologists believe, however, that the total deforested area of Amazonia was not large enough to drive such drastic changes in $\mathrm{CO}_{2}$ (McMichael et al. 2012).

Assessing the extent to which pre-Columbians modified Amazonian ecosystems is one of the most controversial topics in South American paleoecology and archaeology. Some argue that large-scale, pre-Columbian impacts mostly occurred in areas such as riverine forests and that impacts in interfluvial forests may have been minimal and localized (McMichael et al. 2012). Others suggest that large-scale impacts were widespread (Erickson 2008) and left long-lasting legacies in forest biodiversity (Levis et al. 2017).

\section{Mapping pre-Columbian \\ land-use in Amazonia}

In light of this lack of consensus regarding the extent of past anthropogenic disturbance of Amazonia's forests and its effect on global climate, it is important to bring together archaeologists, geographers and paleoecologists to develop a common methodology to assess and map how land was used in pre-Columbian Amazonia. With this in mind, we created a PAGES LandCover6k sub-group called "Mapping pre-Columbian land-use in Amazonia". After securing funding from INQUA's Humans and the Biosphere Commission (HabCom) and the Spanish SIMULPAST project, 16 researchers from seven countries met in Barcelona, Spain, in June 2016 to develop a common research methodology. A second workshop in Trinidad, Bolivia, in October 2017, included 15 researchers from six countries. These meetings focused on: (i) how to extrapolate past land-cover changes from a small number of documented archaeological sites to the entire Amazonia; (ii) what kind of proxies should be used to infer past changes in land use; and (iii) what should be considered as a baseline towards which changes in land cover can be quantified.

\section{Method and datasets}

To date, efforts to map pre-Columbian human occupation in Amazonia have been largely based on geospatial models. McMichael et al. $(2014,2017)$ used locations of known archaeological sites to infer preColumbian settlement patterns in Amazonia, and Levis et al. (2017) used 1170 forest plots of the Amazon Tree Diversity Network (ATDN) to infer pre-Columbian legacies in modern vegetation assemblages. The main problem with these approaches is that the number of sites available is very small and often spatially biased. Lack of mapped archaeological sites in a given area within Amazonia could be due to the fact that large areas have never been surveyed, rather than the nonexistence of sites.

The "Mapping pre-Columbian land use in Amazonia" group concluded that two parallel lines of research are required. The first focuses on improving the quality of existing models by increasing the size of the database of pre-Columbian archaeological sites in Amazonia (Fig. 1). Archaeological

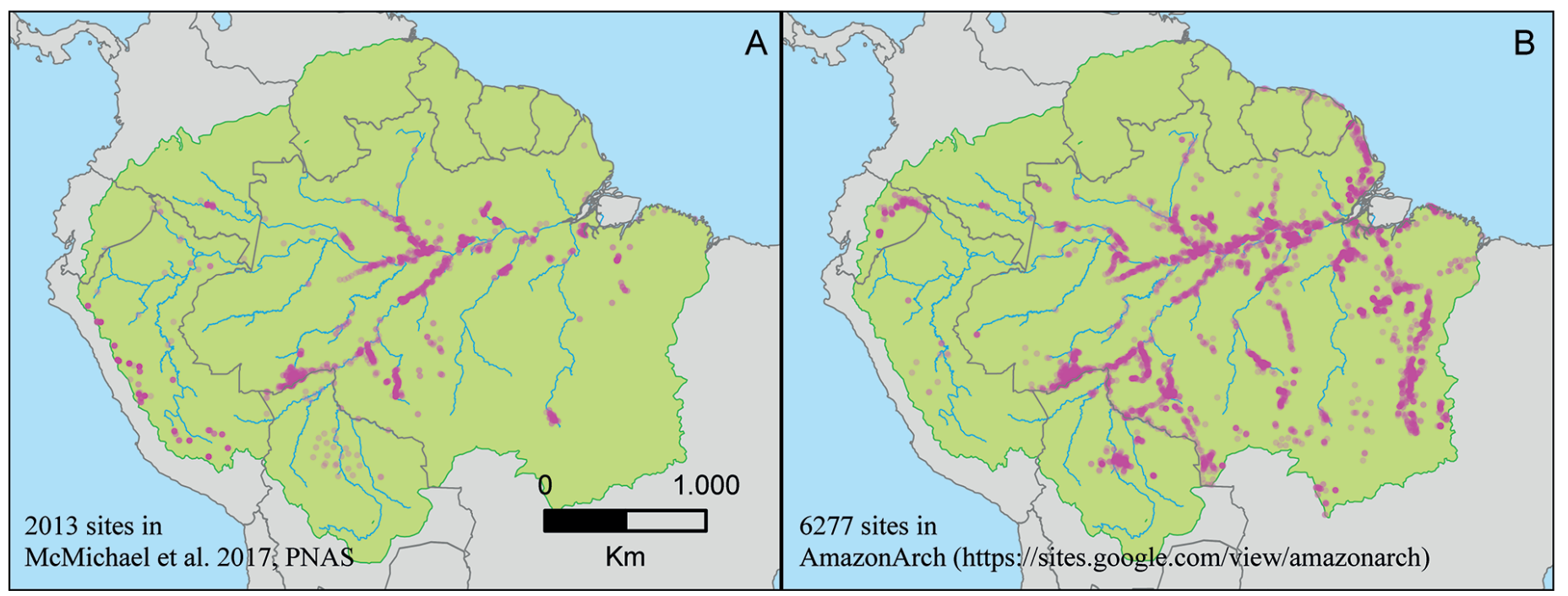

Figure 1: Comparison between the number of archaeological sites (pink dots) used in (A) McMichael et al. (2017), and (B) the number of archaeological sites contained in AmazonArch. The green area represents Amazonia in sensu latissimo (as in Eva et al. 2005), consisting of a core sub region, Amazonia in sensu stricto, plus four peripheral sub regions: Andes, Planalto, Guiana and Gurupí. 


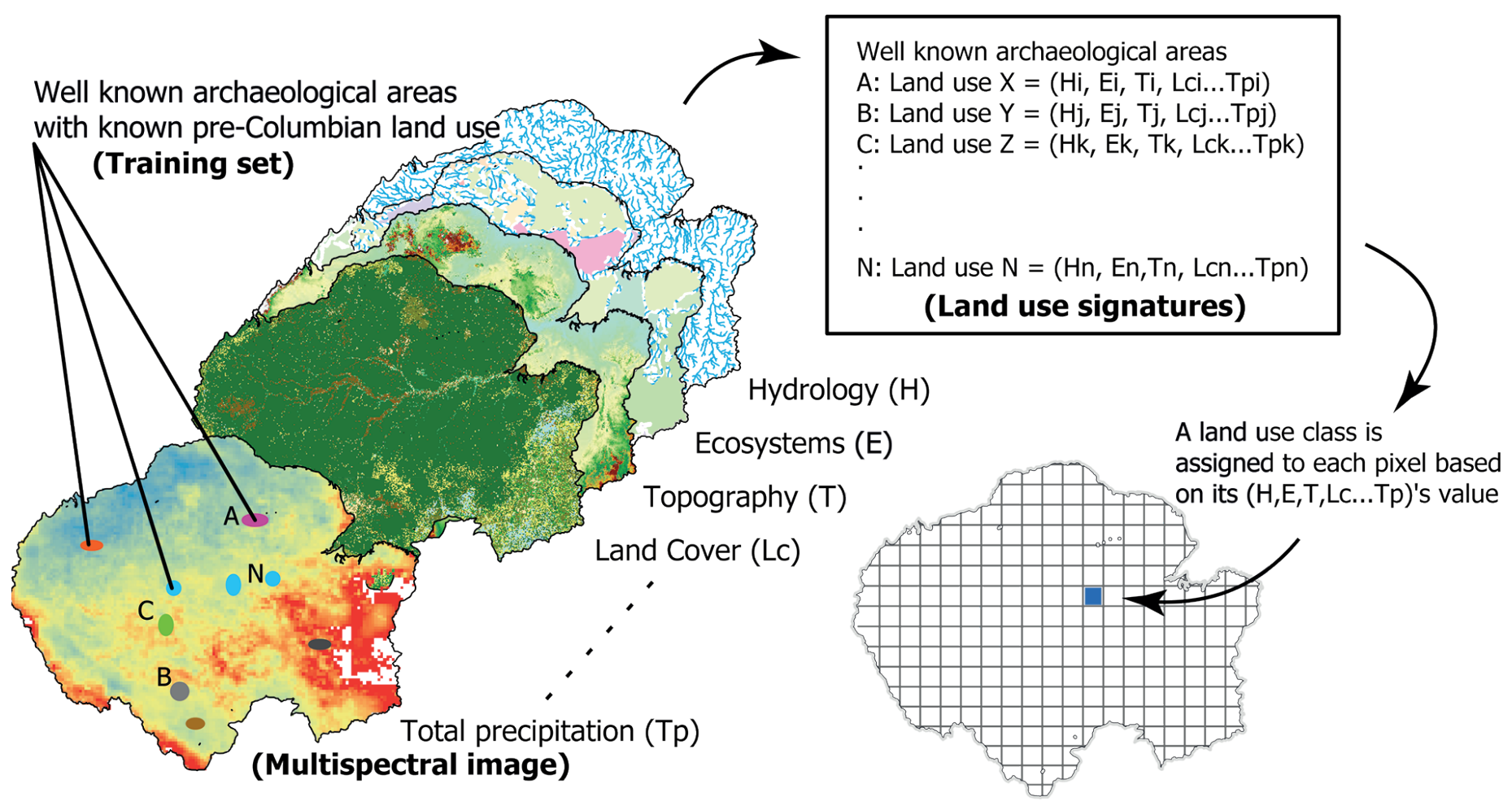

Figure 2: Steps in the supervised classification of pre-Columbian land use in Amazonia.

sites are often documented in Spanish or Portuguese books, journals or reports, and sometimes are stored in researchers' personal databases; for these reasons they are often overlooked by English-speaking researchers. Compiling data about these sites can significantly improve the database in a relatively short time and with limited effort. The second goal includes concentrating our efforts on devising a methodology to include and document, with empirical data, more nuanced forms of pre-Columbian land-use than previously modeled.

We started to compile and digitize all the available data about pre-Columbian archaeological sites in Amazonia, including: (i) geographic coordinates and radiocarbon dates associated with each site; (ii) site characteristics - size, type (i.e. lithic, ceramic, rock art, presence of anthropogenic soils, etc.); and (iii) the availability of ecological, ethnobotanical and archaeobotanical studies in the surrounding areas. The result, called AmazonArch (Amazonian Archaeological Sites Network), is a georeferenced database that allows researchers to share data and information about archaeological sites distributed within Amazonia. AmazonArch's main goal is to gather archaeological data that can be used by network members and other researchers under a data-sharing and data-use policy (https://sites.google.com/ view/amazonarch).

The group is also working to "fill the gaps" by assessing the environmental impact that pre-Columbian populations had at a regional scale in well-known archaeological areas (i.e. the terra preta or Amazonian dark earth sites in Brazil or the Monumental Mounds region in Bolivia) and extrapolate the data from these case studies to the rest of Amazonia using a supervised classification algorithm (Fig. 2). The used algorithm was originally developed to classify land cover in remote sensing imagery (Richards and Jia 1999). Our plan is to use it to classify Amazonia on the basis of several layers of information, where each layer will be treated by the algorithm as if it was a spectral band in a multispectral image. We will use the following "spectral bands": digital elevation model, climate, soil map, distance to water bodies, water chemistry, and vegetation. The group identified 19 well-known archaeological areas that will serve as "training fields" and seven land-use classes that will be used to classify the whole of Amazonia. The algorithm will take into account the environmental parameters (the "spectral bands") associated with each well-known archaeological site (the "training set") and will assign the land-use classes of the wellknown archaeological area to each pixel that has a similar "spectrum" (above a given threshold). This is still a work in progress as we address several problems encountered. The first one is the difficulty of estimating land use in the well-known archaeological areas. Only recently have archaeologists started to examine the archaeological evidence outside the habitation sites, where most of the artifacts are found, so we know far more about terra preta (the area where people lived) than we know about terra mulata (the area that was under cultivation) and less about adjacent agroforest management.

The ultimate goal is to develop a basin-wide model (Fig. 1) with the supervised classification approach that contains more nuanced land-use data. We believe it is of great importance to start tackling the problem and to establish a replicable and robust methodology that allows the continuous improvement and updating of the pre-Columbian land-use maps as new data become available. We expect the results of these two approaches will, with time, converge towards more accurate and comprehensive reconstructions of land use in pre-Columbian Amazonia.

\section{AFFILIATIONS}

${ }^{1} \mathrm{CaSEs}$ - Complexity and Socio-Ecological Dynamics Research Group, Pompeu Fabra University, Barcelona, Spain

${ }^{2}$ Department of Ecosystem and Landscape Dynamics, University of Amsterdam, The Netherlands ${ }^{3}$ Research Group in Archeology, Mamirauá Institute for Sustainable Development, Tefé, Brazil

\section{CONTACT}

Umberto Lombardo: umberto.lombardo@upf.edu

\section{REFERENCES}

Denevan WM (2014) J Lat Am Geogr 13: 207-221

Dull RA et al. (2010) Ann Assoc Am Geogr 100: 755-771

Erickson CL (2008) In: Silverman H, Isbell WH (Eds) Handbook of South American archaeology. Springer, 157-183

Eva HD et al. (2005) Synthesis of the results from an expert consultation workshop organized by the European Commission in collaboration with the Amazon Cooperation Treaty Organization - JRC Ispra, 7-8 June 2005. Luxembourg, EC: 40

Levis C et al. (2017) Science 355: 925-931

McMichael CH et al. (2012) Science 336: 1429-1431

McMichael CH et al. (2014) Proc R Soc B Biol Sci 281: 20132475

McMichael CNH et al. (2017) PNAS 114: 522-527

Richards JA, Jia X (1999) Remote sensing digital image analysis - Third edition, Springer, $494 \mathrm{pp}$ 